\title{
PENGGUNAAN SISTEM STRUKTUR RANGKA ATAP TIPE PELENGKUNG 3 SENDI
}

\author{
Frederikus D. Ndouk ${ }^{[1]}$, Mauritius I. R. Naikofi ${ }^{[1]}$, Krisantos Ria Bela ${ }^{[1]}$, \\ Don G.N da Costa ${ }^{[1,2]}$ \\ ${ }^{[1]}$ Program Studi Teknik Sipil, Fakultas Teknik, Universitas Katolik Widya Mandira \\ ${ }^{[2]}$ Penulis Korespondensi, Program Studi Teknik Sipil, Fakultas Teknik, \\ Universitas Katolik Widya Mandira \\ Email:pratama.dicky26@yahoo.com,mauritiusnaikofi@yahoo.co.id,krisantos_bela@yahoo.com, \\ dnoesaku@gmail.com
}

\begin{abstract}
ABSTRAK
Selama ini sistem struktur rangka atap gedung rumah tinggal dan perkantoran didominasi oleh tipe rangka konvensional. Penggunaan sistem struktur pelengkung 3 sendi hanya familiar untuk bangunan gudang dan sejenisnya. Tujuan penelitian ini adalah untuk mengidentifikasi kelayakan penggunaan tipe pelengkung 3 sendi pada atap gedung rumah tinggal dengan bentang $9 \mathrm{~m}$. Skenario penelitian difokuskan pada perhitungan dengan menggunakan SNI 7973-2013 yaitu Spesifikasi Desain untuk Konstruksi Kayu dan metode Analisa Struktur Statis Tertentu untuk Struktur Pelengkung 3 Sendi berdasarkan panjang model bentang kuda-kuda yaitu $9 \mathrm{~m}$ dengan kemiringan atap $30^{\circ}$. Hasil perhitungan menunjukkan bahwa 1). Tipe pelengkung 3 sendi layak digunakan karena tahanan tekan terkoreksi dan tariknya memenuhi kriteria keamanan 2). Jarak antara kuda-kuda rangka atap mempengaruhi stabilitas (dimensi) rangka batang. Implikasinya adalah bahwa pembangunan atap rumah tinggal dapat menggunakan sistem struktur pelengkung 3 sendi dengan bahan dasar material kayu Kode E20 dengan Mutu B.
\end{abstract}

Kata kunci: Kemiringan Atap, Pelengkung 3 Sendi, Rangka Atap Kayu, Stabilitas Struktur.

\begin{abstract}
So far, the system of the roof structure of residential and office buildings is dominated by conventional frame types. The use of a 3-joint arch structure system is only familiar to warehouse buildings and the like. The purpose of this study is to identify the feasibility of using type 3 joint arches on the roof of a residential building. The research scenario is focused on calculations using SNI 7973-2013, namely Design Specifications for Wooden Construction and Specific Static Structural Analysis Methods for 3 Joint Arch Structures based on the length of the truss span model, which is $9 \mathrm{~m}$. The calculation result indicates that 1). The 3-joint curve type is worth using as it proves stable and safe 2). The distance between the truss of the roof truss affects the dimensions of the truss. The implication is that the construction of the roof of a residential house can use a 3-joint arch structure system while the basic material for modeling uses Code E2O wood material with Quality B, depending on the length of the span and the slope of the roof.
\end{abstract}

Keywords: Slope of Roof, 3 Joint Arch, Wooden Roof Frame, Structural Stability.

\section{PENDAHULUAN}

Pembangunan gedung dalam hal ini rumah tinggal menjadi hal yang utama bagi 
masyarakat karena termasuk kebutuhan pokok, namun tidak semua kelompok masyarakat dapat segera menyelesaikan pekerjaan pembangunan rumah tinggal mereka, karena adanya keterbatasan biaya. Tidak jarang ditemui bahwa sejumlah besar bangunan rumah masih tertunda pelaksanaan konstruksinya pada bagian struktur atap. Hal itu mengindikasikan bahwa terdapat atau adanya problem penyelesaian konstruksi dari aspek pendanaan. Sejalan dengan fenomena tersebut, terpikirkan bahwa diperlukan suatu upaya penelusuran faktor-faktor apa saja yang memengaruhi nilai konstruksi atap bangunan gedung. Dari sejumlah kemungkinan, hasil pemikiran awal mengarah pada pengaruh aspek desain/tipe struktur atap karena komponen rangka atap tersebut merupakan salah satu elemen struktur dengan biaya konstruksi yang tinggi. Biaya tinggi konstruksi tersebut tidak saja berasal dari komponen biaya material (biasanya menggunakan kayu Kelas I ataupun baja dan/atau baja ringan); serta bahan penutup atap genteng, sirap, spandek dan sejenisnya; namun juga dari komponen biaya kerja (ongkos tukang) dan peralatan kerja.

Selama ini tipe struktur rangka atap rumah tinggal maupun fasilitas umum lainnya mengikuti pola konvensional yaitu terdiri dari kaki kuda-kuda, batang tarik, batang tekan (tiang nok dan rangka penyokong). Tujuan penelitian ini adalah untuk mengidentifikasi kelayakan penggunaan tipe atap kayu konstruksi pelengkung 3 sendi sebagai pengganti model atap kayu konvensional. Pilihan tipe atap tersebut berkorelasi kuat dengan aspek biaya konstruksi (Pangaribuan, 2014) maupun keamanan bangunan terhadap beban gempa (Iswanto, 2007). Pada keamana bangunan, perencanaan perlu dilakukan berdasarkan acuan standar yang berlaku (Wijaya \& Pranata, 2014) Dasar pertimbangannya adalah penggunaan tipe konstruksi pelengkung tiga sendi berdampak pada penggunaan jumlah elemen struktur rangka batang yang lebih sedikit dibandingkan dengan tipe kuda-kuda konvensional, sehingga lebih ringan dan mudah dikerjakan. Skenario analisis difokuskan pada simulasi nilai struktural model atap pelengkung tiga sendi untuk bentang hingga $9 \mathrm{~m}$ dan kemiringan atap $30^{\circ}$.

\section{PERSYARATAN KAYU STRUKTURAL}

\subsection{Kuat Acuan Kayu}

Berdasarkan modulus elastisitas lentur yang diperoleh secara mekanis, kuat acuan kayu dapat dilihat pada Tabel 1dan rasio kekuatan berdasarkan kelas mutu kayu terdapat pada Tabel 2. 
Tabel 1. Kuat acuan kayu (MPa) berdasarkan pemilihan secara mekanis

\begin{tabular}{ccccccc}
\hline $\begin{array}{c}\text { Kode } \\
\text { Mutu }\end{array}$ & $\begin{array}{c}\text { Modulus } \\
\text { elastisitas } \\
\text { lentur, } \boldsymbol{E}_{\boldsymbol{w}}\end{array}$ & $\begin{array}{c}\text { Kuat } \\
\text { lentur, } \\
\boldsymbol{F}_{\boldsymbol{b}}\end{array}$ & $\begin{array}{c}\text { Kuat tarik } \\
\text { sejajar } \\
\text { serat, } \boldsymbol{F}_{\boldsymbol{t}}\end{array}$ & $\begin{array}{c}\text { Kuat tekan } \\
\text { sejajar } \\
\text { serat, } \boldsymbol{F}_{\boldsymbol{c} / /}\end{array}$ & $\begin{array}{c}\text { Kuat tekan } \\
\text { tegak lurus } \\
\text { serat, } \boldsymbol{F}_{\boldsymbol{c} \perp}\end{array}$ & $\begin{array}{c}\text { Kuat } \\
\text { geser, }\end{array}$ \\
\hline \hline E26 & 26000 & 71 & 65 & 54 & 24 & 6,9 \\
E25 & 25000 & 67 & 63 & 53 & 23 & 6,8 \\
E24 & 24000 & 64 & 60 & 52 & 22 & 6,7 \\
E23 & 23000 & 61 & 57 & 50 & 21 & 6,5 \\
E22 & 22000 & 58 & 54 & 4 & 20 & 6,4 \\
E21 & 21000 & 54 & 51 & 47 & 19 & 6,2 \\
E20 & 20000 & 51 & 48 & 45 & 18 & 6,1 \\
E19 & 19000 & 48 & 45 & 43 & 17 & 5,9 \\
E18 & 18000 & 45 & 42 & 41 & 16 & 5,7 \\
E17 & 17000 & 41 & 39 & 40 & 15 & 5,6 \\
E16 & 16000 & 38 & 36 & 39 & 14 & 5,4 \\
E15 & 15000 & 35 & 33 & 36 & 13 & 5,3 \\
E14 & 14000 & 32 & 30 & 35 & 12 & 5,1 \\
E13 & 13000 & 29 & 27 & 33 & 11 & 5,0 \\
E12 & 12000 & 25 & 24 & 31 & 11 & 4,8 \\
E11 & 11000 & 22 & 21 & 29 & 10 & 4,7 \\
E10 & 10000 & 19 & 18 & 29 & 9 & 4,5 \\
E9 & 9000 & 16 & 15 & 26 & 8 & 4,3 \\
E8 & 8000 & 12 & 12 & 24 & 7 & 4,2 \\
E7 & 7000 & 9 & 9 & 22 & 6 & 4,1 \\
\hline
\end{tabular}

Sumber: Sumarni, 2007

Tabel 2. Kelas mutu kayu.

\begin{tabular}{lc}
\hline Kelas Mutu & Rasio Kekuatan \\
\hline \hline $\mathrm{A}$ & 0,80 \\
$\mathrm{~B}$ & 0,63 \\
$\mathrm{C}$ & 0,50 \\
\hline \multicolumn{2}{l}{ Sumber: Sumarni, 2007 }
\end{tabular}

\subsection{Batang Tarik}

Batang tarik merupakan elemen struktur yang menerima gaya normal berupa gaya tarik. Menurut Sumarni (2007) komponen struktur tarik direncanakan dengan mengikuti Persamaan (1) :

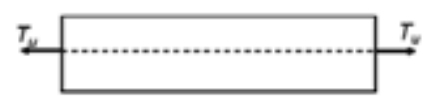

Gambar 1. Batang Tarik 


$$
T_{u} \leq T^{\prime}
$$

Keterangan:

$\mathrm{T}_{\mathrm{u}}=$ gaya tarik terfaktor, $(\mathrm{kN}$ atau $\mathrm{N})$

$\mathrm{T}^{\prime}=$ tahanan tarik terkoreksi, $(\mathrm{kN}$ atau $\mathrm{N})$

Gaya atau tegangan tarik sejajar serat aktual didasarkan atas luas penampang neto dan tidak boleh melebihi nilai desain terkoreksi seperti dinyatakan pada Persamaan (2).

$$
T^{\prime}=F_{t}{ }^{\prime} \times A_{n}
$$

Keterangan:

$\mathrm{F}_{\mathrm{t}}{ }^{\prime}=$ kuat tarik sejajar serat terkoreksi, $\left(\mathrm{N} / \mathrm{mm}^{2}\right)$

$\mathrm{A}_{\mathrm{n}}=$ luas penampang neto, $\left(\mathrm{mm}^{2}\right)$

\subsection{Batang Tekan}

Batang tekan merupakan elemen struktur yang menerima gaya normal berupa gaya tekan. Menurut Sumarni (2007) komponen struktur tekan direncanakan dengan mengikuti Persamaan (3) dan Persamaan (4):

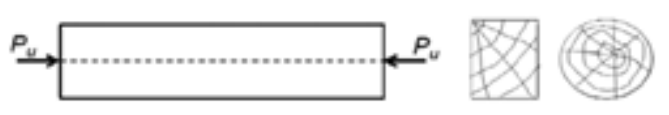

Gambar 2. Batang tekan

$$
\begin{aligned}
& P_{u} \leq P^{\prime} \\
& P^{\prime}=F_{c}{ }^{\prime} \times A_{g}
\end{aligned}
$$

Keterangan:

$\mathrm{P}_{\mathrm{u}}=$ gaya tekan terfaktor, $(\mathrm{kN}$ atau $\mathrm{N})$

$\mathrm{P}^{\prime}=$ kapasitas tekan terkoreksi, $(\mathrm{kN}$ atau $\mathrm{N})$

$\mathrm{F}_{\mathrm{c}}{ }^{\prime}=$ kuat tekan sejajar serat terkoreksi, $\left(\mathrm{N} / \mathrm{mm}^{2}\right)$

$\mathrm{A}_{\mathrm{g}}=$ luas penampang bruto, $\left(\mathrm{mm}^{2}\right)$

Analisa batang tekan harus memenuhi beberapa kriteria berikut:

1) Panjang efektif batang

Panjang batang tak terkekang atau panjang bagian batang tak terkekang, $l$, harus diambil sebagai jarak pusat ke pusat pengekang lateral. Panjang efektif batang tekan, $l_{e}$, untuk arah yang ditinjau diambil, $K_{e} . l$. Dimana $K_{e}$ adalah faktor panjang tekuk untuk komponen struktur tekan. Nilai $K_{e}$ untuk beberapa jenis kondisi kekangan ujung dan untuk keadaan goyangan serta tanpa goyangan dilihat pada Gambar 3. 


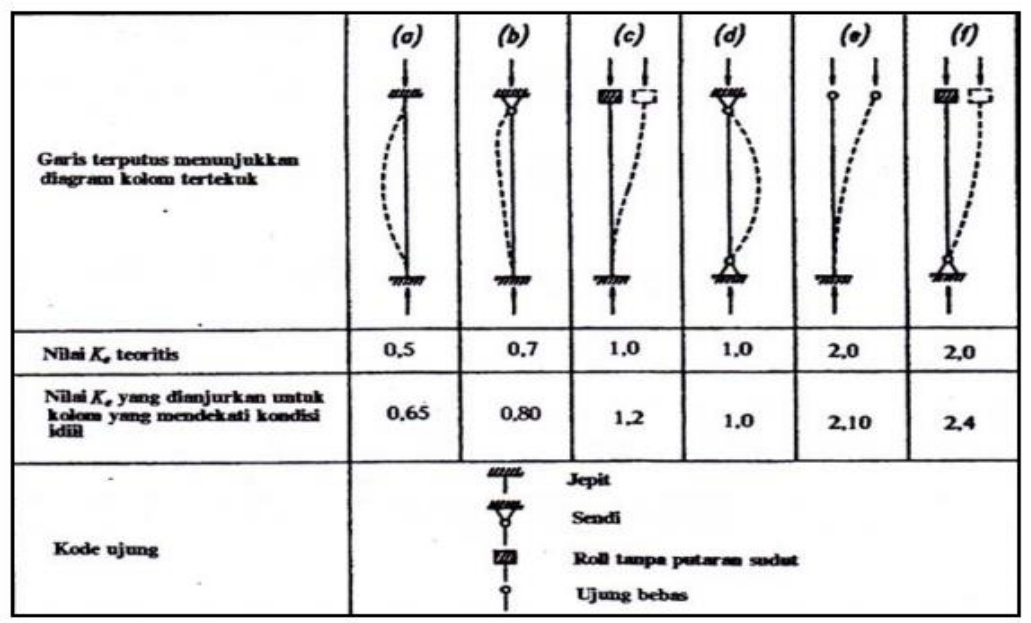

Gambar 3. Nilai faktor panjang tekuk Sumber: SNI 7973-2013

2) Kelangsingan batang

Merupakan perbandingan antara panjang efektif batang pada arah yang ditinjau terhadap jari-jari girasi, $i_{x}$, penampang batang pada arah tersebut. Ditentukan dengan menggunakan Persamaan (5) dan Persamaan (6).

$$
\begin{gathered}
\frac{K_{e} \cdot l}{i_{x}} \leq 1,75 \\
i_{x}=\sqrt{\frac{I_{x}}{A}}
\end{gathered}
$$

Keterangan:

$\mathrm{i}_{\mathrm{x}} \quad=0,289 \mathrm{~h}$ (untuk penampang persegi)

$\mathrm{I}_{\mathrm{x}} \quad=$ momen inersia, $\left(\mathrm{mm}^{4}\right)$

$\mathrm{K}_{\mathrm{e}} \quad=$ koefisien tekuk

$1=$ panjang batang, $(\mathrm{mm})$

3) Tahanan tekan batang

Tahan tekan batang terkoreksi ditetapkan menggunakan Persamaan (7):

$P^{\prime}=C_{p} \times P_{o}^{\prime}=C_{p} \times A \times F_{c}^{\prime}$

Keterangan:

$\mathrm{C}_{\mathrm{p}} \quad$ = faktor kestabilan batang tekan

$\mathrm{P}_{0}{ }^{\prime} \quad=$ tahanan tekuk aksial terkoreksi sejajar serat

A $=$ luas penampang, $\left(\mathrm{mm}^{2}\right)$

$\mathrm{F}_{\mathrm{c}}{ }^{\prime} \quad=$ kuat tekan terkoreksi

Nilai $\mathrm{C}_{\mathrm{p}}$ dihitung menggunakan Persamaan (8) sampai dengan Persamaan (10):

$$
C_{p}=\frac{1+\alpha_{c}}{2 c}-\sqrt{\left(\frac{1+\alpha_{c}}{2 c}\right)^{2}-\frac{\alpha_{c}}{c}}
$$




\section{Keterangan:}

c = konstanta batang tekan, dengan ketentuan sebagai berikut:

$=0,80$, untuk batang masif

$=0,85$, untuk tiang pancang bundar

$=0,90$, untuk kayu laminasi structural

$$
\alpha_{c}=\frac{\phi_{s .} P_{e}}{\lambda . \phi_{c .} P_{o}}
$$

Keterangan:

$\phi_{\mathrm{s}} \quad=$ tahanan stabilitas $=0,85$

$\mathrm{P}_{\mathrm{e}} \quad=$ tahanan tekuk kritis (Euler)

$\lambda=$ faktor waktu

$\phi_{\mathrm{c}} \quad=$ tahanan tekan $=0,9$

$\mathrm{P}_{\mathrm{o}} \quad=$ tahanan tekuk aksial terkoreksi sejajar serat

$$
P_{e}=\frac{\pi^{2} \cdot E_{05}^{\prime} \cdot A}{\left(\frac{K_{e} \cdot L}{i_{x}}\right)^{2}}
$$

Keterangan:

$\mathrm{E}_{05^{6}}{ }^{\circ} \quad=\mathrm{E} 05 \mathrm{x}$ faktor koreksi

Faktor koreksi dari SNI 7973-2013 Tabel 4.3.1: faktor koreksi untuk kayu gergajian

$\mathrm{E}_{05} \quad=0,67 \mathrm{E}_{\mathrm{w}}(\mathrm{MPa})$

\section{METODE PENELITIAN}

\subsection{Jenis Data}

Kombinasi data lapangan dan data literatur diperlukan untuk kajian penelitian ini. Data lapangan meliputi jenis dan tipe konstruksi atap bangunan rumah penduduk dalam kawasan perkotaan Kupang yang saat ini sedang dalam tahapan konstruksi. Nantinya, durasi konstruksi pekerjaan atap konvensional tersebut didata sebagai pembanding dan/atau informasi pendukung penelitian ini. Data sekunder diperoleh tidak saja dari hasil studi literatur namun juga dari berbagai buku pedoman dan/atau standar perencanan konstruksi atap bangunan gedung di Indonesia.

\subsection{Tahapan Penelitian}

Jenis dan/atau tahapan penelitian yang direncanakan disajikan pada diagram alir penelitian Gambar 4. Luaran penelitian difokuskan pada aspek kelayakan teknis dan 
ekonomi dari penggunaan tipe struktur kuda-kuda dan tipe pelengkung 3 sendi. Kelayakan teknis didasarkan pada nilai stabilitas strukturnya sedangkan kelayakan ekonomi didasarkan pada indikasi penghematan volume material konstruksi dan/atau biaya konstruksi (ongkos kerja tukang). Apabila tahanan tekan terkoreksi maupun tahanan tarik lebih kecil dari nilai yang diijinkan, maka penggunaan dimensi kuda-kuda dan jarak gording pada model pelengkung 3 sendi ini dinyatakan aman (tidak membahayakan keselamatan penggunanya).

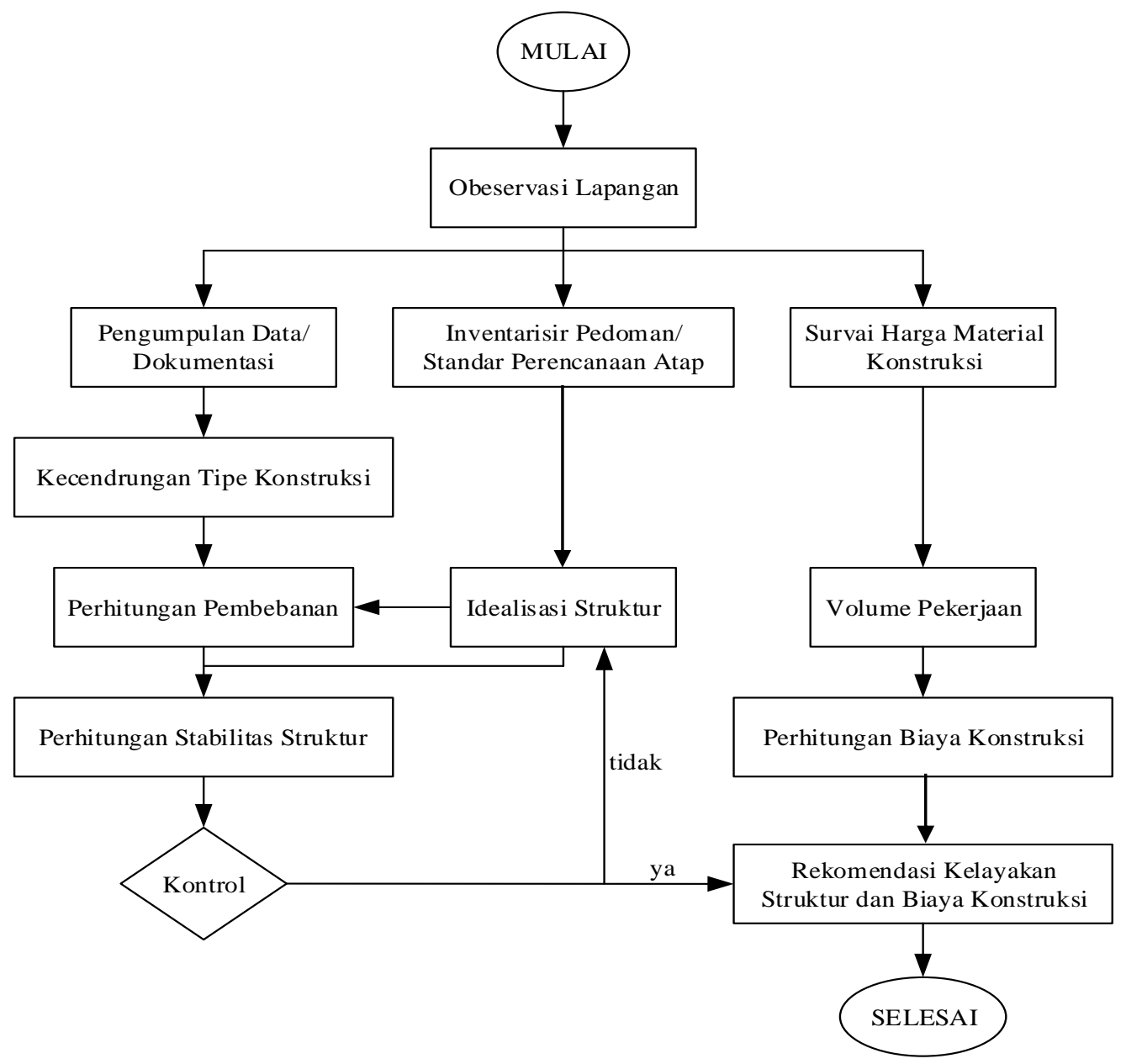

Gambar 4. Diagram alir penelitian.

\section{ANALISA DAN PEMBAHASAN}

\subsection{Tipe Batang Tunggal dan Pemilihan Material Pelengkung 3 Sendi}

Tipe yang digunakan untuk perencanaan struktur rangka atap kuda-kuda adalah model pelengkung 3 sendi sebagaiman tertera pada Gambar 5. Konstruksi atap 
menggunakan kuda-kuda kayu dengan panjang bentang $9 \mathrm{~m}$. Kemiringan atap dipilih $30^{\circ}$ karena berhubungan dengan berat beban yang dipikulnya (Meidani, dkk., 2018). Jenis material kayu relatif murah, mudah ditemukan, mudah dikerjakan serta memiliki nilai struktural yang tinggi. Nilai struktural dimaksud adalah memiliki kekuatan tekan dan tarik yang memadai karena beban utama yang dipikulnya adalah tegangan dan lendutan.

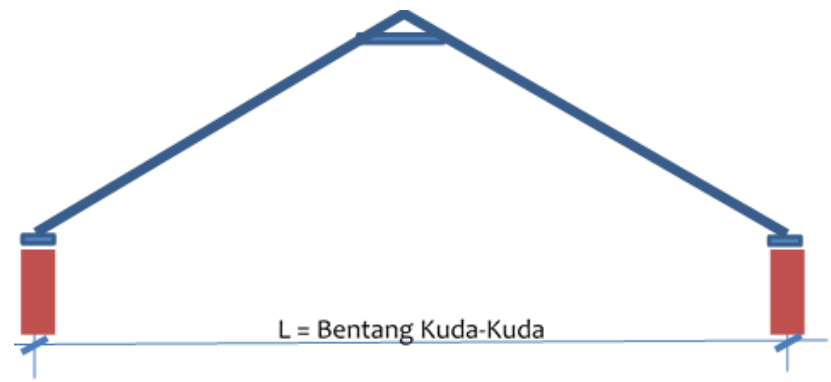

Gambar 5. Pemilihan tipe kuda-kuda pelengkung 3 sendi

Model pelengkung 3 sendi ini memungkinkan terjadinya penghematan material dan biaya konstruksi karena dalam model pelengkung 3 sendi ini tidak terdapat elemen batang tarik/tekan (tiang nok dan/atau batang penyokong kaki kuda-kuda) yang biasanya ada pada tipe struktur kuda-kuda konvensional sebagaimana terlihat dalam Gambar 6.
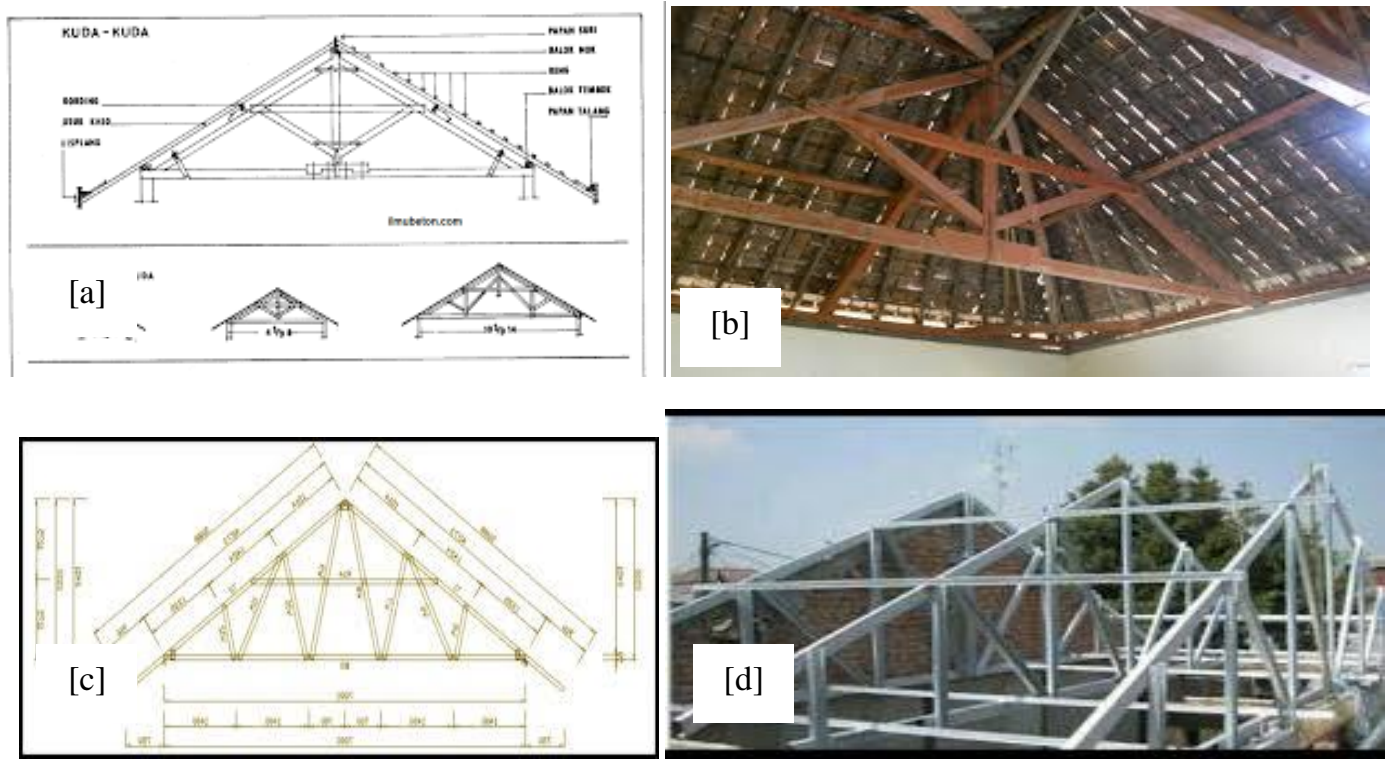

Gambar 6. Tipe kuda-kuda atap konvensional 


\subsection{Analisa Pembebanan}

1) Gording

Dimensi

Jarak antara gording

Beban pada gording:

Berat sendiri atap seng

Beban hidup

Beban angin

Beban mati

Momen terfaktor

$1,2 \mathrm{D}+1,6 \mathrm{~L}+0,8 \mathrm{~W}_{\text {tekan }}$

$$
\begin{array}{llll}
\mathrm{M}_{\mathrm{ux}}= & 310,12 \mathrm{Nm} \\
\mathrm{M}_{\mathrm{uy}}= & 519,18 & \mathrm{Nm}
\end{array}
$$

$1,2 \mathrm{D}+1,6 \mathrm{~L}+0,8 \mathrm{~W}_{\text {hisap }}$

Kayu digunakan:

$$
\mathrm{M}_{\mathrm{ux}}=
$$$$
\text { 279,01 Nm }
$$$$
\mathrm{M}_{\mathrm{uy}}=
$$$$
519,18 \quad \mathrm{Nm}
$$

Kode : E20

Mutu : B

\section{Kontrol tegangan lentur:}

$$
\begin{aligned}
& \frac{M u x_{\text {tekan }}}{\lambda \cdot \phi \cdot M x^{\prime}}+\frac{M u y_{\text {tekan }}}{\lambda \cdot \phi \cdot M y^{\prime}} \leq 1,00 \quad \text { hasil } \quad: 0,02 \\
& \frac{M u x_{\text {isap }}}{\lambda \cdot \phi \cdot M x^{\prime}}+\frac{M u y_{\text {isap }}}{\lambda \cdot \phi \cdot M y^{\prime}} \leq 1,00 \text { hasil } \quad: 0,02
\end{aligned}
$$

\section{Kontrol lendutan balok:}

Lendutan maksimum

$$
\Delta_{\max }=\mathrm{L} / 300=\quad 4 \mathrm{~mm}
$$

Lendutan total

$$
\Delta_{\text {tot }}=\operatorname{sqrt}\left(\Delta \mathrm{x}^{2}+\Delta \mathrm{y}^{2}\right)<\Delta_{\max } \quad 2,19 \mathrm{~mm}
$$

2) Kuda-kuda

Ukuran balok kuda kuda

$$
\begin{array}{lrrl}
\qquad \begin{array}{lll}
b= \\
h=
\end{array} & 8 & \mathrm{~cm} \\
& 12 & \mathrm{~cm} \\
\text { Berat sendiri kuda kuda/ titik buhul } & 299,30 & \mathrm{~N} \\
\text { Beban akibat gording } & 34,56 & \mathrm{~N} \\
\text { Beban terhadap atap } & 96 & \mathrm{~N}
\end{array}
$$$$
\text { Beban akibat gording } \quad 34,56 \mathrm{~N}
$$$$
\text { Beban hidup } \quad 1000 \mathrm{~N}
$$ 
Tabel 3. Beban angin isap dan angin tekan

\begin{tabular}{ccccc}
\hline Titik & Batang & Panjang $(\mathrm{m})$ & Angin tekan $(\mathrm{N})$ & Angin isap $(\mathrm{N})$ \\
\hline \hline A & 1 & 2,60 & 187,06 & $-374,12$ \\
B & 2 & 2,60 & & $-374,12$ \\
C & 1 & 2,60 & 187,06 & $-374,12$ \\
& 2 & 2,60 & & $-374,12$ \\
\hline
\end{tabular}

Tabel 4. Beban per titik buhul

\begin{tabular}{ccccc}
\hline \multirow{2}{*}{ Joint } & \multicolumn{4}{c}{ Beban (N) } \\
\cline { 2 - 5 } & Mati & Hidup & Angin Kiri & Angin Kanan \\
\hline \hline A & 280,21 & 1000 & 187,06 & \\
B & 280,21 & 1000 & & $-374,12$ \\
C & 429,86 & 1000 & 187,06 & $-374,12$ \\
\hline
\end{tabular}

Tabel 5. Analisa gaya batang

\begin{tabular}{ccccc}
\hline \multirow{2}{*}{ Batang } & \multicolumn{4}{c}{ Gaya akibat beban $(\mathrm{N})$} \\
\cline { 2 - 5 } & Mati & Hidup & Angin & Total \\
\hline \hline 1 & $-508,53$ & -1183 & 0,00 & $-1691,54$ \\
2 & $-508,53$ & -1183 & 866,84 & $-824,70$ \\
\hline
\end{tabular}

Kontrol tahanan tekan terkoreksi:

$$
\mathrm{P}^{\prime}=\mathrm{F}_{\mathrm{c}}{ }^{*} * \mathrm{~A}_{\text {gross }}=18,04 \mathrm{kN}<50 \mathrm{kN}
$$

Kontrol tahanan tarik:

$$
\begin{aligned}
& \mathrm{T}_{\mathrm{u}}= \\
& 1691,54 \mathrm{~N} \\
& \mathrm{~T}^{\prime}=\mathrm{F}_{\mathrm{t}}{ }^{*} \mathrm{~A}_{\mathrm{n}}>\mathrm{T}_{\mathrm{u}} \\
& 128019,90 \quad \mathrm{~N}
\end{aligned}
$$

Penggunaan model rangka batang kuda-kuda dengan mutu kayu B, dimensi 8/12 untuk bentang $9 \mathrm{~m}$ kemiringan $30^{\circ}$ aman untuk digunakan sebagai elemen struktur rangka atap tipe pelengkung 3 sendi. Dengan ketentuan antara lain: jarak antar kuda-kuda diperhatikan sesuai dengan perhitungan, karena berhubungan terhadap dimensi gording (balok) dengan kontrol terhadap lendutan balok yang terjadi.

Karena jumlah elemen struktur rangka kuda-kuda yang digunakan jauh lebih sedikit dari model kuda-kuda atap konvensional (tanpa tiang nok dan rangka pengaku kaki kuda-kuda) maka penggunaan tipe pelengkung 3 sendi ini terindikasi lebih murah dari penggunaan tipe kuda-kuda konvensional. Selain itu, efisiensi biaya konstruksi juga bersumber dari komponen biaya ongkos kerja tukang. Indikasi ini pada dasarnya sejalan dengan hasil studi Pangaribuan (2014) yang membandingkan efisiensi biaya konstruksi kuda-kuda kayu dan baja ringan. 


\section{PENUTUP}

Dari hasil analisis dan pembahasan dapat disimpulkan bahwa penggunaan konstruksi atap berbahan dasar kayu dengan sistem struktur pelengkung 3 sendi merupakan opsi strategis ekonomis karena penggunaan elemen rangka batang yang lebih sedikit dibandingkan dengan model struktur rangka atap kayu maupun baja ringan tipe konvensional, serta model struktur yang sederhana (hanya batang tekan \& gording) tersebut terbukti aman dan hemat biaya material maupun ongkos kerja konstruksi.

\section{DAFTAR PUSTAKA}

Awaludin, A. (2005). Dasar-dasar Perencanaan Sambungan Kayu. Biro Penerbit KMTS UGM. Yogyakarta.

Iswanto, D. (2007). Kajian Terhadap Struktur Rangka Atap Kayu Rumah Tahan Gempa Bantuan P2KP. Jurnal Ilmiah Perancangan Kota dan Permukiman, Vol. 6, No. 1 Maret. Yogyakarta.

Massafra, A., Prati, D., Predari, G., and Gulli, R. (2020). Wooden Truss Analysis, Preservatoin Strategies, and Digital Documentation Through Parametric 3D modeling and HBIM Workflow. Sustainability, 2020, 12, 4975, doi:10.3390/su12124975.

Meidiani, S., Riwayati, S., dan Imriany, D. (2018). Analisa Perbandingan Perencanaan Portal Frame Perletakkan Jepit-Jepit dan Sendi-Sendi dengan Variasi Kemiringan Sudut Atap. Jurnal Teoritis dan Terapan Bidang Rekayasa Sipil, Vol. 6, No. 2.

Pangaribuan, M., R. (2014). Baja Ringan Sebagai Pengganti Kayu dalam Pembuatan Rangka Atap Bangunan Rumah Masyarakat. Jurnal Teknik Sipil dan Lingkungan, Vol. 2, No. 4.

Pynkyawati, T., Amiruloh, M., Asvitasari, A., Hakim, N., K., dan Ginanjar, E. (2015). Model Atap Bangunan Ramah Lingkungan Ditinjau dari Pengolahan Air Hujan pada Desain Kampus PT Dahana, Subang-Jawa Barat. Jurnal Itenas, Vol. 3, No. 1, https://ir.lib.uwo.ca/etd/4851.

SNI 7973-2013. Spesifikasi Desain untuk Konstruksi Kayu. Badan Standarisasi Nasional (BSNI). Jakarta.

Stevenson, S. (2017). Analysis of Framing Failures in Wood-Frames Residential Roofs Under Wind Load. Electronic Thesis and Dissertation Repository, 4851. The University of Western Ontario.

Sumarni, S. (2007). Struktur Kayu. Lembaga Pengembangan Pendidikan (LPP) UNS dan UPT Penerbitan dan Percetakan UNS (UNS Press). Surakarta.

Triono, Anggraeni, D., dan Ammar M. (2020). Pemodelan Struktur Rangka Atap Kayu Aula Bentang 15 M. Jurnal Rekayasa Teknologi Nusa Putra, Vol. 9, No. 1.

Wijaya, Micahel dan Pranata, Y.A., 2014, Perancangan Perangkat Lunak Perencanaan Sambungan Kayu Berdasarkan SNI 7973-2013 dengan Alat Sambung Baut, Jurnal Teknik Sipil, vol. 10, no 2, 2014, 143-165. https://doi.org/10.28932/jts.v10i2.1389 